\title{
Levothyroxine and the risk of adverse pregnancy outcomes in women with subclinical hypothyroidism: a systematic review and meta-analysis
}

Magnus Bein ${ }^{1,2 \dagger}$, Oriana Hoi Yun Yu ${ }^{3,4+}$, Sonia Marzia Grandi ${ }^{5}$, Francesca Y. E. Frati 6 , Ihab Kandil2 and Kristian B. Filion ${ }^{4,2,7^{*}}$ (D)

\begin{abstract}
Background: Levothyroxine replacement therapy may decrease the risk of adverse pregnancy outcomes among women with subclinical hypothyroidism $(\mathrm{SCH})$. The aim of this study is to conduct a systematic review and metaanalysis to examine the risk of adverse pregnancy, perinatal, and early childhood outcomes among women with $\mathrm{SCH}$ treated with levothyroxine.

Methods: A systematic literature search was conducted using Ovid-Medline, Ovid-EMBASE, Pubmed (non-Medline), Ebsco-CINAHL Plus with full text and Cochrane Library databases. Randomized controlled studies (RCTs) and observational studies examining the association between treatment of SCH during pregnancy and our outcomes of interest were included. Studies that compared levothyroxine treatment versus no treatment were eligible for inclusion. Data from included studies were extracted and quality assessment was performed by two independent reviewers.

Results: Seven RCTs and six observational studies met our inclusion criteria. A total of 7342 individuals were included in these studies. RCTs demonstrated several sources of bias, with lack of blinding of the participants or research personnel; only one study was fully blinded. In the observational studies, there was moderate to serious risk of bias due to lack of adjustment for certain confounding variables, participant selection, and selective reporting of results. Pooled analyses showed decreased risk of pregnancy loss (RR: 0.79; 95\% Cl: 0.67 to 0.93 ) and neonatal death (RR: $0.35 ; 95 \% \mathrm{Cl}: 0.17$ to 0.72 ) associated with levothyroxine treatment during pregnancy among women with $\mathrm{SCH}$. There were no associations between levothyroxine treatment and outcomes during labour and delivery, or cognitive status in children at 3 or 5 years of age.

(Continued on next page)
\end{abstract}

\footnotetext{
*Correspondence: kristian.filion@mcgill.ca

${ }^{+}$Magnus Bein and Oriana Hoi Yun Yu contributed equally to this work.

${ }^{4}$ Center for Clinical Epidemiology, Lady Davis Institute, Jewish General Hospital, Montreal, Quebec H3T 1E2, Canada

${ }^{2}$ Department of Medicine, McGill University, Montreal, Quebec, Canada

Full list of author information is available at the end of the article
}

C C The Author(s). 2021 Open Access This article is licensed under a Creative Commons Attribution 4.0 International License, which permits use, sharing, adaptation, distribution and reproduction in any medium or format, as long as you give appropriate credit to the original author(s) and the source, provide a link to the Creative Commons licence, and indicate if changes were made. The images or other third party material in this article are included in the article's Creative Commons licence, unless indicated otherwise in a credit line to the material. If material is not included in the article's Creative Commons licence and your intended use is not permitted by statutory regulation or exceeds the permitted use, you will need to obtain permission directly from the copyright holder. To view a copy of this licence, visit http://creativecommons.org/licenses/by/4.0/ The Creative Commons Public Domain Dedication waiver (http://creativecommons.org/publicdomain/zero/1.0/) applies to the data made available in this article, unless otherwise stated in a credit line to the data. 
(Continued from previous page)

Conclusion: Treatment of SCH with levothyroxine during pregnancy is associated with decreased risks of pregnancy loss and neonatal death. Given the paucity of available data and heterogeneity of included studies, additional studies are needed to address the benefits of levothyroxine use among pregnant women with SCH.

Keywords: Subclinical hypothyroidism, Levothyroxine, Pregnancy outcomes

\section{Background}

Subclinical hypothyroidism $(\mathrm{SCH})$ is a common biochemical entity identified in women during pregnancy. $\mathrm{SCH}$ is diagnosed when the thyroid stimulating hormone (TSH) is elevated with a normal free thyroxine (FT4) level. Although most women with $\mathrm{SCH}$ are asymptomatic, previous studies have shown that $\mathrm{SCH}$ may be associated with adverse outcomes during pregnancy [1-3].

The thyroid hormone, FT4, is necessary for fetal growth and development. Insufficient thyroid hormone has been shown to impair fetal growth [4] and brain development [5] and it may have negative effects on neonatal survival [4]. Women with overt hypothyroidism during pregnancy require levothyroxine treatment [6]. However, there is uncertainty as to whether women with $\mathrm{SCH}$ during pregnancy should be treated as the benefits of treating $\mathrm{SCH}$ during pregnancy have not been consistently demonstrated [6-9].

Several studies have examined the association of $\mathrm{SCH}$ and adverse outcomes during pregnancy and long-term outcomes in mothers and children including pregnancy loss, pre-term delivery, gestational diabetes, gestational hypertension, eclampsia, placental abruption, low birth weight, and childhood cognitive outcomes [10-14]. Several of these studies reported increased risks of these outcomes among women with untreated $\mathrm{SCH}$ during pregnancy $[2,3,14]$. However, there was heterogeneity between studies with respect to the timing of initiation of levothyroxine, the study population, the underlying cause of $\mathrm{SCH}$, and the estimated treatment effects $[1,2$, 15, 16]. As a result of the discordant findings, the 2017 American Thyroid Association (ATA) guidelines recommended levothyroxine therapy for women with $\mathrm{SCH}$ (defined as a TSH level greater than the pregnancyspecific range) and thyroid autoimmune disease (defined as the presence of anti-thyroid peroxidase antibodies [TPOAb)]). For women with negative TPOAb levels, the guidelines recommended treatment with levothyroxine therapy for TSH levels greater than 10mIU/L. [9] However, levothyroxine therapy was not recommended for women with no antibodies and a TSH within the pregnancy-specific reference range.

Previous meta-analyses have been performed on this topic. However, these meta-analyses have focused on comparing women with $\mathrm{SCH}$ with euthyroid women during pregnancy $[10,12]$ or only included randomized controlled trials (RCTs), which are very few to this date [16]. To our knowledge, only two meta-analyses have assessed the effects of levothyroxine treatment among women with $\mathrm{SCH}$ during pregnancy. The meta-analysis by Rao et al. (2019) [17], pooled studies including women with $\mathrm{SCH}$ and euthyroid women with thyroid autoimmune disease and compared women treated with levothyroxine versus no treatment. The meta-analysis by Nazapour et al. (2019), [18], compared women with $\mathrm{SCH}$ during pregnancy treated with levothyroxine with women who were euthyroid. However, this metaanalysis performed a subgroup analysis comparing the risk of pregnancy loss associated with levothyroxine treatment versus no treatment among women with $\mathrm{SCH}$ and found that levothyroxine was associated with a decreased risk of pregnancy loss among $\mathrm{SCH}$ women treated with levothyroxine during pregnancy (odds ratio: 0.78; 95\% confidence interval [CI]: 0.66-0.94) [18]. Although women with $\mathrm{SCH}$ treated with levothyroxine have normal TSH levels similar to euthyroid women, it is uncertain whether euthyroid women are comparable to women with treated $\mathrm{SCH}$.

Due to the lack of good quality evidence for treatment of SCH during pregnancy, it is unclear whether levothyroxine treatment should be given to women with isolated $\mathrm{SCH}$ during pregnancy [9]. To examine this question, we conducted a systematic review and meta-analysis of studies comparing the risk of maternal and fetal outcomes in women with $\mathrm{SCH}$ who were treated or not treated with levothyroxine during pregnancy.

\section{Methods}

Our systematic review was conducted following a prespecified protocol and is reported based on the guidelines outlined in the Preferred Reporting Items for Systematic Reviews and Meta-Analyses (PRISMA) statement [19]. The study protocol is available upon request from the corresponding author. The inclusion criteria and analyses described below do not deviate materially from those specified in this protocol.

\section{Literature search}

We systematically searched Ovid MEDLINE (Appendix 1), Ovid EMBASE (Appendix 2), Ebsco-CINAHL Plus with Full Text (Appendix 3), Pubmed (for articles not indexed in Medline) (Appendix 4), and Cochrane Library 
from inception to July 18, 2018 to identify studies that examined the association between treatment of $\mathrm{SCH}$ during pregnancy and adverse pregnancy outcomes. A medical librarian (FF) designed and conducted the searches (see Appendix for full search strategies). The Ovid-Medline search was peer reviewed by a second librarian using the Peer Review of Electronic Search Strategies (PRESS) guideline [20]. No language restrictions were applied. We also scanned the references of relevant articles, searched for citing articles (snowballing), and conducted a search of the grey literature to retrieve studies not identified by our primary search. We reviewed previous systematic reviews and meta-analyses of levothyroxine treatment among women with $\mathrm{SCH}$ during pregnancy and retrieved studies not identified in our search.

\section{Study selection}

We included interventional and observational studies that reported the risk of adverse pregnancy outcomes with and without levothyroxine treatment among women with $\mathrm{SCH}$. Inclusion was restricted to studies in which $\mathrm{SCH}$ was defined by a TSH level between 2.5 and $10 \mathrm{mIU} / \mathrm{L}$ at any time during pregnancy and included women with $\mathrm{SCH}$ identified pre-pregnancy. We based our definition of SCH on the 2011 ATA guidelines [21], which is a broader definition compared to that included in the more recent 2017 ATA guidelines which recommends treatment for $\mathrm{SCH}$ during pregnancy depending on the presence of thyroid autoimmune disease [9]. Furthermore, given that the ATA guidelines on management of $\mathrm{SCH}$ during pregnancy are similar for women with pre-existing and newly diagnosed $\mathrm{SCH}$, studies that included women with pre-existing $\mathrm{SCH}$ and were initiated on levothyroxine treatment pre-conception were included. The use of this broader definition allowed for the inclusion of all available evidence. Studies were required to report at least one of the following outcomes: pregnancy loss (spontaneous abortion and stillbirths), spontaneous abortion (pregnancy loss before 20 weeks of gestation), and stillbirth (death of an infant occurring after 20 weeks of gestation). We also included the assessment of other outcomes reported in the studies selected, including intrauterine growth restriction, preterm delivery, preterm labor, low Apgar score $(<7$ at $5 \mathrm{~min}$ after birth), low birth weight, or behavioural and cognitive development of the child. We excluded uncontrolled studies, systematic reviews and meta-analyses, crosssectional studies, letters to the editor and commentaries, and animal studies. Finally, we excluded conference abstracts as they contain insufficient information for quality assessment.

After removing duplicates, two independent reviewers screened the titles and abstracts of identified publications, with any publication deemed potentially relevant by either reviewer carried forward to full-text review. Discrepancies during full-text review between reviewers were resolved by consensus or a third reviewer (IK or KBF).

\section{Quality assessment and data extraction}

Quality assessment and data extraction were performed for all included studies by two independent reviewers (MB and $\mathrm{OY}$ ), with disagreements resolved by consensus or by a third reviewer (IK or KBF). The Cochrane Risk of Bias tool was used for RCTs [22] and the Risk of Bias In Non-randomised Studies of Interventions (ROBINS)-I tool was used for observational studies [23]. We extracted information on study design, study population characteristics (size, demographics, location, study period), $\mathrm{SCH}$ definition, key findings, and frequencies and effect estimates and 95\% CIs for the association between levothyroxine and adverse pregnancy outcomes. For observational studies, adjusted effect estimates were extracted.

\section{Statistical analysis}

Given the paucity of RCTs that assessed the risk of adverse events during pregnancy with levothyroxine treatment among women with subclinical hypothyroidism, we performed our primary analysis, pooling findings from RCTs and observational studies [24]. By including the totality of evidence in this area of research, we increase precision of our estimates [24]. We also performed a secondary analysis whereby we used meta-regression to study the effects of study design (i.e. RCTs and observational studies) on the association between levothyroxine treatment and pregnancy loss and other adverse outcomes among women with $\mathrm{SCH}$. For each binary outcome, we pooled risk ratios (RR) using Dersimonian and Laird random-effects models with inverse variance weighting [25], applying the Jackson and Knapp-Hartung extensions [26, 27]. A continuity correction of 0.5 was used for both the treatment and reference groups when a frequency of zero was present. For continuous outcomes, we estimated the weighted mean difference using a similar approach [28]. Heterogeneity was assessed by the tau-squared estimators, and the $\mathrm{I}^{2}$ statistics. We conducted the analyses using the meta package [29] in $R$ [30].

\section{Sensitivity analyses}

We performed six sensitivity analyses. First, to address the influence of levothyroxine treatment for women with $\mathrm{SCH}$ caused by an autoimmune condition, we repeated our analyses including only studies that addressed the risk of adverse pregnancy outcomes among women with TPOAb positivity who 
were treated with levothyroxine versus untreated women. Second, the meta-analysis was repeated after excluding studies that assessed women with a history of infertility or recurrent miscarriages, as women with these conditions may have a higher risk of adverse pregnancy outcomes. Third, given that one of the prospective clinical trials did not utilize randomization compared to the other prospective clinical studies [31], we repeated our primary metaanalysis excluding this study. Fourth, we performed stratified analyses based on the quality of RCTs and observational studies that assessed the association between levothyroxine use and the risk of pregnancy loss among women with $\mathrm{SCH}$ during pregnancy. Fifth, we conducted an influence analysis in assessing the association between levothyroxine treatment and pregnancy loss to determine if any study had a significant impact on our results. Finally, we repeated our meta-analyses using a continuity correction of 0.1 for both the treatment and reference groups.

\section{Results}

Seven RCTs and six cohort studies were included from a total of 3953 articles identified by our search (Fig. 1). Thyroid hormone levels of subjects included in the studies were consistent in terms of the definition of $\mathrm{SCH}$, with some minor heterogeneity for the specific populations the subjects were drawn from. For RCTs and observational studies, the intervention was initiation of levothyroxine for women identified with $\mathrm{SCH}$. The timing of initiation of treatment, the dosing, and adjustment of treatment varied widely across studies (Table 1).

\section{Quality assessment}

RCTs

One RCT fulfilled all quality criteria [37] and was classified as high-quality study and the remaining six RCTs were of moderate quality (Table S1). Five studies did not meet the criteria in at least three domains of bias [31, 35, 38, 39, 42] and one study was

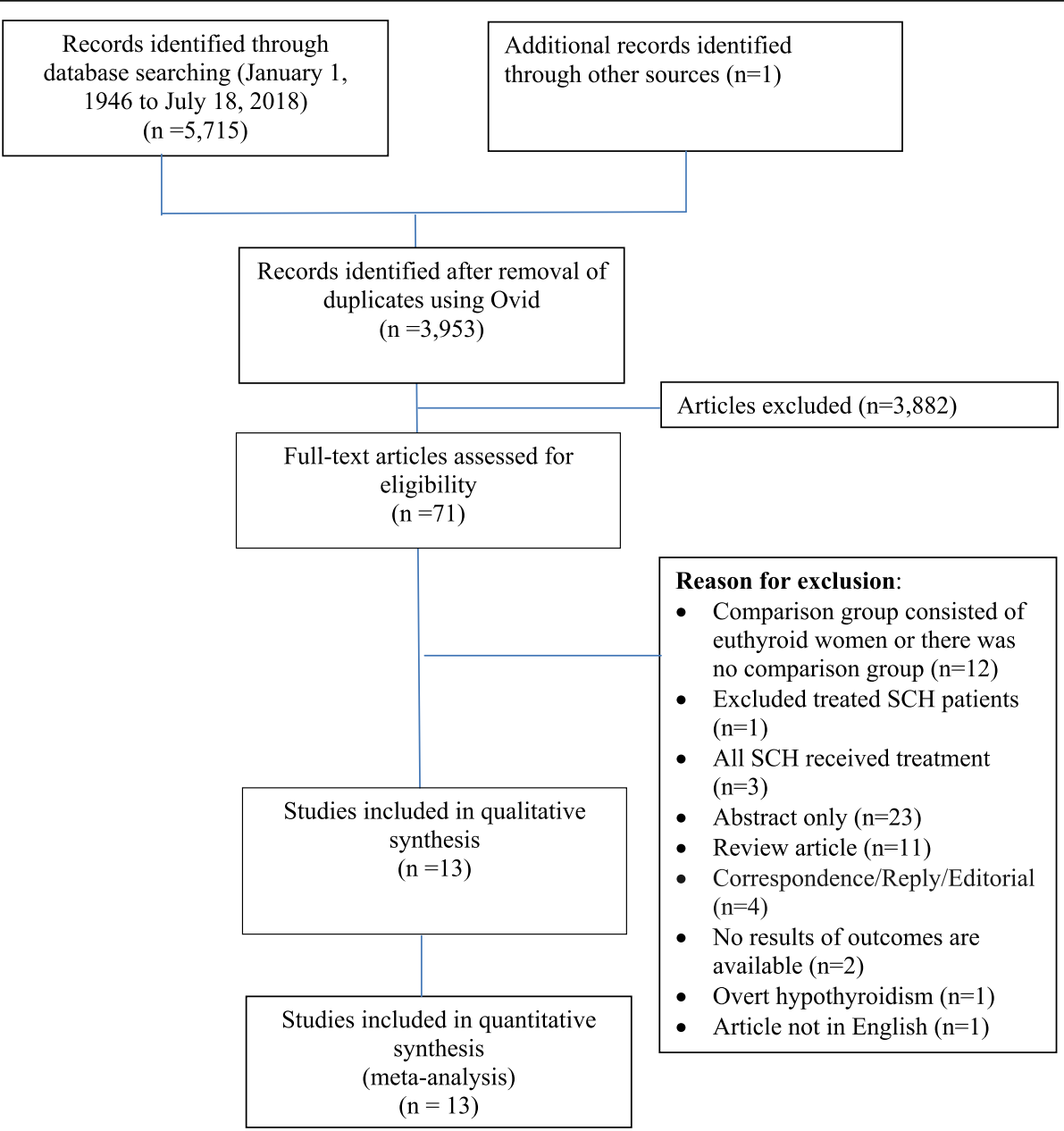

Fig. 1 Flowchart diagram (Figure adapted from PRISMA 2009 Flow Diagram) [19] 
Table 1 Summary of studies included in the systematic review and meta-analysis

\begin{tabular}{|c|c|c|c|c|c|c|}
\hline $\begin{array}{l}\text { Study and } \\
\text { research } \\
\text { institution }\end{array}$ & $\begin{array}{l}\text { Study design } \\
\text { and Size }(\mathrm{N})\end{array}$ & $\begin{array}{l}\text { Geographic } \\
\text { Region and } \\
\text { Period }\end{array}$ & $\begin{array}{l}\text { Serum TSH and } \\
\text { fT4 for SCH } \\
\text { diagnosis }\end{array}$ & $\begin{array}{l}\text { Gestational age } \\
\text { levothyroxine } \\
\text { started with initial } \\
\text { dose and } \\
\text { adjustment }\end{array}$ & Outcomes & Findings \\
\hline $\begin{array}{l}\text { Bernardi } \\
\text { et al.; } 2013 \\
\text { [32] } \\
\text { University of } \\
\text { Chicago }\end{array}$ & $\begin{array}{l}\text { Cohort study } \\
N=39\end{array}$ & $\begin{array}{l}\text { United States } \\
\text { July 2004- } \\
\text { December } 2011\end{array}$ & $\begin{array}{l}\mathrm{TSH}>2.5 \mathrm{mIU} / \mathrm{L} \\
\text { with normal fT4 } \\
\text { level }(0.9-1.7 \mathrm{ng} / \\
\mathrm{dL}) \text { measured } \\
\text { before conception }\end{array}$ & $\begin{array}{l}\text { Initiated if SCH was } \\
\text { identified pre- } \\
\text { conception } \\
\text { Initial dose and } \\
\text { adjustment } \\
\text { unknown. }\end{array}$ & Live-birth rates & $\begin{array}{l}\text { Among women with a } \\
\text { history of }>2 \text { pregnancy } \\
\text { losses and SCH, women } \\
\text { who received treatment } \\
\text { for SCH did not have an } \\
\text { increased live birth rate } \\
\text { compared to women } \\
\text { who did not receive } \\
\text { levothyroxine treatment } \\
\text { (per-pregnancy live birth } \\
\text { rate: SCH treated: } 48 \% \\
\text { (22/46) vs. SCH } \\
\text { untreated: } 52 \%(12 / 23) \text {. }\end{array}$ \\
\hline
\end{tabular}

\section{Maraka et al. Retrospective 2016 [33] Cohort} Mayo Clinic
Rochester,

Minnesota January 2011

December 2013

TSH 2.5-10 mlU/L in first trimester \& 3-10 $\mathrm{mIU} / \mathrm{L}$ in

other trimesters normal fT4 (>0.8 $\mathrm{ng} / \mathrm{dL}$ )
Started at median GA 9.1 weeks

Pregnancy loss defined as miscarriage and stillbirth, preterm delivery ( $<37$ weeks), premature rupture of membranes, placental abruption, gestational diabetes, gestational hypertension, preeclampsia, eclampsia, intrauterine growth restriction, birth weight, Apgar score at $5 \mathrm{~min}$, admission to the neonatal intensive care unit, neonatal death (during immediate postpartum period until discharge of the mother) and duration of hospital stay.

$\begin{array}{ll}\text { Al-Anbari, } & \text { Prospective } \\ 2017 & \text { study } \mathrm{N}=149\end{array}$

High Institute of Infertility diagnosis and assisted reproductive technologies/AlNahrain University, Iraq
$\mathrm{TSH}>2.5 \mathrm{mlU} / \mathrm{L} \quad$ Initiated if SCH was prior to conception identified preconception
Pregnancy rate, miscarriage rate, multiple pregnancy rate and live birth rate
Treated pregnancies had a lower birth weights and no Apgar score less than 7. Other pregnancy outcomes were statistically similar between groups. Pregnancy loss OR: 2.44; 95\% Cl: 0.80-8.87 Preterm delivery OR: 3.06; 95\% Cl: 0.96-12.28 Gestational diabetes OR: 3.31; 95\% Cl: 0.91-16.57 Gestational hypertension OR: 0.64; 95\% Cl: 0.231.93

Pre-eclampsia OR: 3.37; 95\% Cl: 0.66-26.84 Premature rupture of membranes OR: 0.71; 95\% Cl: 0.29-1.79 Intrauterine growth restriction OR: 1.45; 95\% Cl: $0.23-28.1$

Placenta previa and placental abruption: not enough events to do multivariate analyses NICU admission OR: 1.94; 95\% Cl: 0.38-15.36 Birth weight $<2500 \mathrm{~g}$

OR: 16.4 ; $95 \% \mathrm{Cl}$ : $2.7-$ 326.9

Neonatal death and congenital malformations: not enough events to do multivariate analyses

Significantly increased pregnancy rate (19/75 among levothyroxine treated versus $8 / 74$ among women not given treatment). No multiple pregnancies in both groups. No difference in miscarriage rate (2/ 75 among levothyroxine treated versus vs 2/74 
Table 1 Summary of studies included in the systematic review and meta-analysis (Continued)

\begin{tabular}{|c|c|c|c|c|c|}
\hline $\begin{array}{l}\text { Study and } \\
\text { research } \\
\text { institution }\end{array}$ & $\begin{array}{l}\text { Study design } \\
\text { and Size }(\mathrm{N})\end{array}$ & $\begin{array}{l}\text { Geographic } \\
\text { Region and } \\
\text { Period }\end{array}$ & $\begin{array}{l}\text { Serum TSH and } \\
\text { fT4 for SCH } \\
\text { diagnosis }\end{array}$ & $\begin{array}{l}\text { Gestational age } \\
\text { levothyroxine } \\
\text { started with initial } \\
\text { dose and } \\
\text { adjustment }\end{array}$ & Outcomes \\
\hline $\begin{array}{l}\text { Maraka et al. } \\
2017 \text { [34] } \\
\text { OptumLabs } \\
\text { Data } \\
\text { Warehouse }\end{array}$ & $\begin{array}{l}\text { Retrospective } \\
\text { Cohort } \\
N=5405\end{array}$ & $\begin{array}{l}\text { United States } \\
\text { January 2010- } \\
\text { December } 2014\end{array}$ & $\begin{array}{l}\text { TSH } 2.5-10 \text { mIU/L } \\
\text { from } 1 \text { month prior } \\
\text { to } 3 \text { months after } \\
\text { first prenatal visit } \\
\text { fT4 } 0.8 \mathrm{ng} / \mathrm{dL} \text { or } \\
\text { total thyroxine } 7.5 \\
\mathrm{mcg} / \mathrm{dL}\end{array}$ & $\begin{array}{l}\text { Started at median } \\
\text { GA } 28.7 \text { weeks } \\
\text { before birth } \\
\text { Unknown initial } \\
\text { dose. } \\
\text { Median dose: } 50 \\
\text { mcg daily (range } \\
\text { 25-300mcg daily) }\end{array}$ & $\begin{array}{l}\text { Pregnancy loss defined } \\
\text { as miscarriage and still- } \\
\text { birth, preterm delivery, } \\
\text { preterm labor, prema- } \\
\text { ture rupture of mem- } \\
\text { branes, placental } \\
\text { abruption, gestational } \\
\text { diabetes, gestational } \\
\text { hypertension, pre- } \\
\text { eclampsia, poor fetal } \\
\text { growth, tachycardia }\end{array}$ \\
\hline
\end{tabular}

Findings

among women not given treatment).

Treatment of SCH was associated with decreased risk of pregnancy loss but was associated with increased risk of other adverse pregnancy related outcomes. Pregnancy loss OR: 0.62; 95\% Cl: 0.48-0.82 Preterm delivery OR: 1.6; 95\% Cl: 1.14-2.24 Preterm labor OR: 1.14; 95\% Cl: 0.89-1.46 Premature rupture of membranes OR: 0.97; 95\% Cl: 0.66-1.42 Placental abruption OR: 1.60; 95\% Cl: 0.65-3.93 Gestational diabetes OR: 1.37; 95\% Cl: 1.05-1.79 Gestational hypertension OR: 1.27; 95\% Cl: 0.881.82

Pre-eclampsia OR: 1.61; 95\% Cl: 1.10-2.37 Poor fetal growth OR: 1.12; 95\% Cl: 0.84-1.5 Tachycardia OR: 1.77; 95\% Cl: 1-3.11

$\begin{array}{ll}\text { Nazarpour } & \text { RCT } \\ \text { et al. 2017 } & N=1294 \\ \text { [35] } & \\ \text { Shahid } & \\ \text { Beheshti } & \\ \text { Medical } & \\ \text { University } & \end{array}$

Tehran, Iran September 2013-February 2016
TSH 2.5-10 mIU/L fT4 1-4.5 TPOAb positive
Started 4 to $8 d$ after prenatal visit, the mean GA at initial visit was 10.8 weeks.

$1 \mathrm{mcg} / \mathrm{kg}$ daily Dose adjustment not described.
Preterm delivery, neonatal admission, placental abruption, still birth, GA mean birth weight, neonate height, birth head circumference, neonatal TSH
There were no significant differences in preterm delivery or neonatal admission between treated and untreated women with SCH $(\mathrm{TSH}<4 \mathrm{mIU} / \mathrm{L})$ treated versus untreated but there were significant differences in preterm delivery and neonatal admission between treated and untreated women with $\mathrm{TSH}>4 \mathrm{mIU} / \mathrm{L}$. There was also a significant decrease in neonatal admission among women treated for $\mathrm{SCH}$ versus women who did not receive treatment [number (\%): 2 (3.6) vs.12 (20.7)] There were no significant differences in placental abruption, still birth, and gestational age between treated versus untreated women with $\mathrm{SCH}$.

There were no significant differences in 
Table 1 Summary of studies included in the systematic review and meta-analysis (Continued)

\begin{tabular}{lllllll}
\hline $\begin{array}{l}\text { Study and } \\
\text { research } \\
\text { institution }\end{array}$ & $\begin{array}{l}\text { Study design } \\
\text { and Size (N) }\end{array}$ & $\begin{array}{l}\text { Geographic } \\
\text { Region and } \\
\text { Period }\end{array}$ & $\begin{array}{l}\text { Serum TSH and } \\
\text { fT4 for SCH } \\
\text { diagnosis }\end{array}$ & $\begin{array}{l}\text { Gestational age } \\
\text { levothyroxine } \\
\text { started with initial } \\
\text { dose and } \\
\text { adjustment }\end{array}$ & Outcomes & Findings \\
& & & & & \\
& & & &
\end{tabular}

$\begin{array}{lll}\text { Nazarpour } & \text { RCT } & \text { Tehran, Iran } \\ \text { et al. } 2018 & N=354 & \text { September } \\ \text { [36] } & & 2013-\text { February } \\ \text { Shahid } & & \\ \text { Beheshti } & & \\ \text { Medical } & & \\ \text { University } & & \end{array}$

TSH $2.5-10 \mathrm{mlU} / \mathrm{L}$
fT4 1-4.5 TPOAb
negative

Started 4-8 days after first prenatal visit, which was at 11.2-12.2 weeks of gestation Dosed at $1 \mathrm{mcg} / \mathrm{kg}$ daily.

Dose adjustment not described
Preterm delivery, placental abruption, stillbirth, neonatal admission, birth weight, mean gestational age neonate height, birth head circumference neonatal TSH

mean birth weight, head circumference and neonate TSH levels between study groups.

Significant difference in pre-term delivery when $\mathrm{TSH}>4 \mathrm{mIU} / \mathrm{L}$ and

treated with levothyroxine versus no treatment, RR: 0.38 ; $95 \%$ Cl: $0.15-$ 0.98. There was no significant difference in the risk of other adverse pregnancy outcomes among women with

$\mathrm{SCH}$ treated versus untreated.

Number (\%) of outcomes treated versus untreated:

Preterm delivery: 18 (9.8) vs. 21 (11.5)

Neonatal admission: 8

(4.5) vs. 9 (4.9)

Placental abruption: 3

(1.6) vs. 0

Stillbirth: 0 vs. 0

Gestational age: 38.03

(1.4) vs. 37.9 (1.5)

Mean (standard

deviation)

Birth weight: $3190.82 \mathrm{~g}$

(455.13) vs. $3203.1 \mathrm{~g}$

(497.1)

Neonate height: $50.1 \mathrm{~cm}$

(2.3) vs. $50.2 \mathrm{~cm}$ (2.7) Birth head

circumference: $34.6 \mathrm{~cm}$

(1.4) vs. $34.7 \mathrm{~cm}$ (1.6)

Neonatal TSH (mIU/L):

$1.1(0.5-1.9)$ vs. 1.1 (0.5-

2.1)

Casey et al. RCT 2017 [37]

$N=677$ women

with $\mathrm{SCH}, 526$

with

hypothyroxinemia
United States

October 2006-

October 2009

$\mathrm{fT} 4<0.86 \mathrm{ng} / \mathrm{dl}$

with TSH between

0.08 and $3.99 \mathrm{mlU} / \mathrm{L}$

Started at GA 10-24 Multiple pregnancy and weeks; average GA

$16.6+/-3$ week

standard deviation

Initial dose $100 \mathrm{mcg}$

daily.

Monthly adjustment

to maintain TSH

$0.1-2.5 \mathrm{mIU} / \mathrm{L}$

Max dose: $200 \mathrm{mcg}$ daily

Treatment group normalized TSH by median of GA 21 weeks neonatal outcomes. For

maternal outcomes:

preterm birth $(<34$

and $<37$ weeks), placental abruption,

gestational

hypertension, preeclampsia,

gestational diabetes. For fetal and neonatal outcomes: stillbirth/ miscarriage, neonatal death, Apgar score at and $5 \mathrm{~min}$, birth weight ( $<10$ percentile), head circumference, respiratory distress syndrome, necrotizing enteritis, bronchopulmonary
No differences in adverse pregnancy and neonatal outcomes between levothyroxine treated versus placebo group. No differences in IQ score at the age of 5 years or death at the age of $<3$ years

between treated and untreated SCH (median IQ score for children in levothyroxine treated group: 97 (95\% Cl: 94 99) versus 94 (95\% Cl: 91-95) in placebo. 
Table 1 Summary of studies included in the systematic review and meta-analysis (Continued)

\begin{tabular}{lllll}
\hline $\begin{array}{l}\text { Study and } \\
\text { research } \\
\text { institution }\end{array}$ & $\begin{array}{l}\text { Study design } \\
\text { and Size (N) }\end{array}$ & $\begin{array}{l}\text { Geographic } \\
\text { Region and } \\
\text { Period }\end{array}$ & $\begin{array}{l}\text { Serum TSH and } \\
\text { fT4 for SCH } \\
\text { diagnosis }\end{array}$ & $\begin{array}{l}\text { Gestational age } \\
\text { levothyroxine } \\
\text { started with initial } \\
\text { dose and } \\
\text { adjustment }\end{array}$ \\
\hline
\end{tabular}
dysplasia, respiratory therapy $>1$ day, number of days in nursery. Annual cognitive testing over first 5 years, IQ at 5 yo. or general conceptual ability at 3 yo

\section{Lazarus et al. RCT 2012 [38] $\quad N=794$}

Kim et al. $\quad$ RCT

2011 [39] $\quad N=64$
Wales \& Cardiff, $\quad$ TSH $>$ 97.5th UK Ospendale percentile and $f$ Sant'Anna, Turin, T4 $<2.5$ th Italy Period of time not mentioned but followed children at age 3 years

Seoul, South Korea

March 2006September 2009

$\mathrm{TSH}>4.5 \mathrm{mlU} / \mathrm{L}$ with normal fT4 (1)
Embryo implantation rate, total amount and administered, number of fertilized oocytes, and good quality embryos, clinical pregnancy rate miscarriage rate, preterm birth ( $<34$ weeks) and fetus $>20$ weeks with signs of life)
Started at approx. Premature rupture of GA 10 weeks membranes, fetal Initial dose $100 \mathrm{mcg}$ macrosomia, gestational daily.

Adjusted by 100 mcg to maintain TSH 2.5-97.5 percentile. $\begin{array}{ll}\text { [40] } & \text { cohort } \\ \text { Beijing } & N=457\end{array}$

Friendship

Hospital of

Capital

Medical

University
Prospective

$\begin{array}{ll}\text { Ju et al. 2016 } & \text { Prospective } \\ \text { [40] } & \text { cohort } \\ \text { Beijing } & N=457 \\ \text { Friendship } & \\ \text { Hospital of } & \\ \text { Capital } & \\ \text { Medical } & \\ \text { University } & \end{array}$

$\begin{array}{ll}\text { Wang et al. } & \text { Prospective } \\ 2012 \text { [41] } & \text { cohort } \\ \text { Liaoning } & N=196 \\ \text { Provincial Key } & \\ \text { Laboratory of } & \\ \text { Endocrine } & \\ \text { Diseases } & \end{array}$

Beijing, China

October 2010-

September 2013

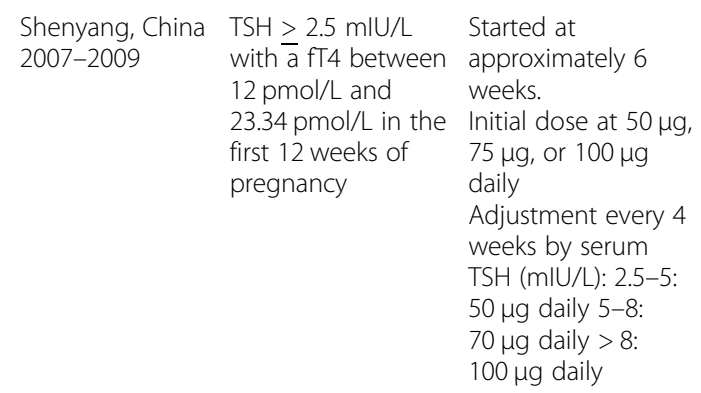
daily

Adjustment every 4 weeks by serum

TSH (mIU/L): 2.5-5:

$50 \mu \mathrm{g}$ daily $5-8$ :

$70 \mu \mathrm{g}$ daily $>8$ :

$100 \mu \mathrm{g}$ daily

TSH $>97.5$ th percentile and fT4 2.5th-97.5th percentile
Started at GA 12-13 IQ at 3 years of age

weeks

Initial dose of 150

mcg daily.

Adjustment 6 weeks after beginning treatment and at 30 weeks $\mathrm{GA}$ to target TSH 0.1-1 mIU/L

Started prior to IVF/ ICSI treatment (before pregnancy). Initial dose $50 \mathrm{mcg}$ daily.

Adjustment: First trimester titration to maintain $\mathrm{TSH}<2.5$ $\mathrm{mIU} / \mathrm{L}$ to max dose $100 \mathrm{mcg}$ daily (12/ 17) and $125 \mathrm{mcg}$ daily $(1 / 17)$ days of rhFSH retrieved, mature, per cycle, and live birth (delivery of diabetes, hypertensive disorders in pregnancy, postpartum hemorrhage, preterm labor, oligohydramnios, fetal distress, and low birth weight
Findings

No significant differences in IQ scores at age 3 years between children born of mothers with $\mathrm{SCH}$ treated versus placebo during pregnancy: $1 \mathrm{Q}$ score treated: 99.2 +/13.3 vs. untreated: 100 +/- 13.3 .

Significant increase in embyro quality and implantation when women with $\mathrm{SCH}$ were treated versus untreated. Significant decrease in miscarriage and increase in live birth rate per cycle when women with

$\mathrm{SCH}$ were treated versus untreated.

Miscarriage rate in treated versus untreated: $0 / 17$ vs. $4 / 12$

Live birth rate per cycle in treated versus untreated: $17 / 32$ vs. $8 / 32$

Overall risk of pregnancy complications in control group significantly higher than in treated group (OR: 1.219; 95\% Cl 1.139-1.304). For single outcomes, there was a statistically increased risk of gestational diabetes among untreated versus treated women with SCH (OR: 1.938; 95\% Cl: 1.267-2.964) and fetal macrosomia (OR:3.081; 95\% Cl: 1.783-5.326).

Spontaneous abortion, Levothyroxine treatment anemia, hypertension, premature delivery, low decreased the incidence birth weight, postpartum hemorrhage, of spontaneous abortions compared to
Apgar score $\leq 7$ at 5 min no treatment but this

was not statistically significant.

Outcomes in treated versus untreated women with $\mathrm{SCH}$ : Spontaneous abortions: 
Table 1 Summary of studies included in the systematic review and meta-analysis (Continued)

\begin{tabular}{lllll}
\hline $\begin{array}{l}\text { Study and } \\
\text { research } \\
\text { institution }\end{array}$ & $\begin{array}{l}\text { Study design } \\
\text { and Size (N) }\end{array}$ & $\begin{array}{l}\text { Geographic } \\
\text { Region and } \\
\text { Period }\end{array}$ & $\begin{array}{l}\text { Serum TSH and } \\
\text { fT4 for SCH } \\
\text { diagnosis }\end{array}$ & $\begin{array}{l}\text { Gestational age } \\
\text { levothyroxine } \\
\text { started with initia } \\
\text { dose and } \\
\text { adjustment }\end{array}$ \\
\hline
\end{tabular}

$\begin{array}{llll}\text { Zhao et al. } & \text { RCT } & \begin{array}{l}\text { Shanghai, China } \\ \text { January 2014- }\end{array} & \text { TSH }>\text { TSH }>3 \mathrm{~m} / \mathrm{mlU} / \mathrm{L} \\ 2018[42] & N=93 & \text { October 2016 } & \\ \text { Shuguang } & & & \\ \text { Hospital } & & \\ \text { Affiliated to } & & \\ \text { Shanghai } & & \\ \text { University of } & & \\ \text { Traditional } & & \\ \text { Chinese } & & \\ \text { Medicine } & \end{array}$

\author{
ZhongDa, China \\ January 2014- \\ May 2014
}

\author{
Outcomes

Outcomes

Findings

dose and

adjustment
2 (7.14\%) vs. 26 (15.47\%) Anemia: 3 (10.71\%) vs.
35 (20.83\%)
Hypertension: 1 (3.57\%)
vs. 2 (1.19\%)
Premature delivery: 0 vs.
9 (5.36\%)
Low birth weight: 0 vs. 4
(2.38\%)
Hemorrhage: 0 vs. 2
(1.19\%)
Apgar score $\leq 7$ at 5
min: 0 vs. $4(2.38 \%)$ complications: no significant different between treated versus untreated groups for individual outcomes. However, for combined outcomes: treatment given during $\mathrm{T} 1 \mathrm{had}$ significantly less complications than women who were not treated (Number of total adverse pregnancy outcomes among women treated at T1: 1/ 31 vs. 10/31 (treated at T2) vs. 12/31 (no treatment).

\section{Started either in $\mathrm{T} 1$ \\ Gestational \\ Pregnancy} at 8-10 weeks or T2 at 13-16 weeks. Initial dose $25 \mathrm{mcg}$ daily.

Max dose: $100 \mathrm{mcg}$ daily hypertension, anemia, gestational diabetes, pre-eclampsia, premature labor, pregnancy loss, post-partum hemorrhage, low birth weight $(<2500 \mathrm{~g})$

$\begin{array}{ll}\text { Zhang et al. } & \text { Retrospective } \\ 2017[12] & \text { cohort } \\ & N=9\end{array}$

TSH 0.27-4.2 mIU/L and fT4 0.93-1.70 $\mathrm{ng} / \mathrm{dL}$ (in T2)
Started in second trimester. Dose at $50 \mathrm{mcg}$ daily
No significant birth weight premature delivery $(0 / 1$ in treated vs. $3 / 8$ untreated), Apgar (10 $+/-0$ in treated vs. $9.8+/-0.61$ untreated), and birth weight $(3.67+/$ $-0.6 \mathrm{~kg}$ in treated vs. $3.48+/-0.54 \mathrm{~kg}$ in untreated) in women with treated and untreated SCH.

Abbreviations: $C /$ confidence intervals; $C / S$ cesarean section; $E R$ emergency room; fT4 free thyroxine; GA gestational age; IQ intelligence quotient; IVF in vitro fertilization, NICU neonatal intensive care unit; OR odds ratio; $R C T$ randomized controlled trial; rhFSH recombinant human follicular stimulating hormone; SCH subclinical hypothyroidism; T1 first trimester; T2 second trimester; TSH thyroid stimulating hormone; yo years old

deficient in two criteria [36]. Six of the included RCTs were randomized [35-39, 42], however half did not perform appropriate allocation concealment [38, $39,42]$. In all except one study [37], participants and personnel were not blinded [31, 35, 36, 38, 39, 42]. Assessors of the outcomes were blinded in four of the seven RCTs [35-38]. Reporting bias was a concern in two RCTs due to selective reporting of subgroup analyses [35, 36].

\section{Observational studies}

The included cohort studies had a moderate to serious risk of bias (Table S2). Three domains of bias drove this overall quality assessment: confounding, participant selection, and selective reporting of results. The lack of control for important confounding variables was moderate to critical in all studies. The risks of selection bias, and bias due to selective reporting of results were moderate in three of six studies [33, 34, 41], with one at 
serious risk [40]. Risk of bias from measurement of outcomes was low to moderate. Interventional risks and missing data biases were low, except in one study [12].

\section{Fetal outcomes}

Congenital malformation, fetal distress, fetal macrosomia, oligohydramnios, placenta previa were reported in single studies and thus meta-analyses were not possible (Table 2). Meta-analyses were performed for the following outcomes: intrauterine growth restriction (2 studies), spontaneous abortion (4 studies), and pregnancy loss (10 studies) (Table 2). Compared with non-use, levothyroxine treatment among women with $\mathrm{SCH}$ was associated with a decreased risk of pregnancy loss (RR: 0.79; 95\% CI: 0.67-0.95) (Fig. 2). When we stratified the metaanalyses by study design, there was a suggestion of greater benefits with respect to pregnancy loss in RCTs (RR: 0.51; 95\% CI: 0.25-1.05) than observational studies (RR: 0.81 ; 95\% CI: 0.62-1.05) but 95\% CIs overlapped between the two (Fig. 3). We did not observe an association between the use of levothyroxine among women with $\mathrm{SCH}$ during pregnancy and the risk of intrauterine growth restriction and spontaneous abortion (Table 2, Table 3 and Figures S1-S2).

\section{Perinatal outcomes}

Levothyroxine treatment among women with $\mathrm{SCH}$ was not associated with placenta abruption, postpartum hemorrhage, premature rupture of membranes, preterm delivery, or preterm labour (Table 2, Table 3 and Figures S3-S7). Four studies examined stillbirth [31, 35, 36, 39] but no stillbirths occurred among study participants.

\section{Neonatal outcomes}

Neonatal outcomes assessed included neonatal death, 5min Apgar score, and low birthweight (Table 2, Table 3). Levothyroxine treatment compared to no treatment among women with $\mathrm{SCH}$ was associated with a decreased risk of neonatal death (RR 0.35; 95\% CI: 0.170.72) (Figure S8). Levothyroxine treatment was not associated with the risk of low 5-min Apgar score (Figure S9) and low birthweight (Figure S10). Additionally, levothyroxine treatment was not associated with head circumference in the two RCTs that reported this outcome (Table 4).

\section{Cognitive outcomes in children at 3 to 5 years of age}

Only two RCTs assessed the association between levothyroxine treatment and behavioral and cognitive

Table 2 Summary of binary outcomes between pregnant women with subclinical hypothyroidism treated with and without levothyroxine, expressed risk ratio (RR) with 95\% confidence intervals (Cl)

\begin{tabular}{|c|c|c|c|}
\hline Outcomes & No. of studies & Pooled sample & $\begin{array}{l}\text { Risk ratio } \\
(95 \% \mathrm{Cl})^{*}\end{array}$ \\
\hline \multicolumn{4}{|l|}{ Fetal } \\
\hline Congenital malformation & 1 & 336 & 0.37 (0.02 to 6.8$)$ \\
\hline Fetal distress & 1 & 457 & 0.78 (0.59 to 1.0$)$ \\
\hline Fetal macrosomia & 1 & 457 & 0.32 (0.19 to 0.56$)$ \\
\hline Intrauterine growth restriction & 2 & 5771 & 1.06 (0.59 to 1.90$)$ \\
\hline Oligohydramnios & 1 & 457 & 1.48 (0.60 to 3.7$)$ \\
\hline Placenta abruption & 5 & 6928 & 0.98 (0.37 to 2.61$)$ \\
\hline Placenta previa & 1 & 366 & 0.49 (0.03 to 9.5$)$ \\
\hline Spontaneous abortion & 4 & 366 & 0.45 (0.13 to 1.56$)$ \\
\hline Pregnancy loss (still births and spontaneous abortions) & 10 & 7342 & 0.79 (0.67 to 0.93 ) \\
\hline \multicolumn{4}{|l|}{ Perinatal } \\
\hline Postpartum hemorrhage & 3 & 746 & 0.88 (0.18 to 4.22$)$ \\
\hline Premature rupture of membranes & 3 & 6228 & 0.94 (0.52 to 1.70$)$ \\
\hline Preterm delivery & 7 & 7217 & 0.77 (0.47 to 1.25 ) \\
\hline Preterm labour & 2 & 5862 & 1.05 (0.56 to 1.97$)$ \\
\hline Still birth & 4 & 536 & NA \\
\hline \multicolumn{4}{|l|}{ Neonatal } \\
\hline APGAR under 7 at five minutes & 3 & 1209 & 0.42 (0.03 to 5.31$)$ \\
\hline Low birth weight & 5 & 1759 & 0.80 (0.26 to 2.43 ) \\
\hline Neonatal death & 2 & 1013 & 0.35 (0.17 to 0.72 ) \\
\hline
\end{tabular}

"When only one study has the reported response, the data summarized are taken from the single study NA No stillbirths were observed in control or treatment groups in any studies reporting this outcome 


\begin{tabular}{|c|c|c|c|c|c|c|c|c|c|}
\hline \multirow{2}{*}{$\begin{array}{l}\text { Study } \\
\text { Al-Anbari } 2017\end{array}$} & \multicolumn{2}{|c|}{$\begin{array}{l}\text { Levothyroxine } \\
\text { Events Total }\end{array}$} & \multicolumn{2}{|c|}{$\begin{array}{l}\text { Control } \\
\text { nts Total }\end{array}$} & & \multirow{2}{*}{$\begin{array}{l}\text { Risk Ratio of } \\
\text { Pregnancy loss } \\
\\
\vdots\end{array}$} & \multirow{2}{*}{$\begin{array}{r}\mathbf{R R} \\
0.42\end{array}$} & $95 \%-\mathrm{Cl}$ & Weight \\
\hline & 2 & 19 & 2 & 8 & & & & {$[0.07 ; 2.49]$} & $1.1 \%$ \\
\hline Bernardi et al. 2013 & 24 & 46 & 11 & 23 & & : & 1.09 & {$[0.66 ; 1.81]$} & $12.9 \%$ \\
\hline Casey et al. 2017 & 4 & 339 & 7 & 338 & & : & 0.57 & {$[0.17 ; 1.93]$} & $2.3 \%$ \\
\hline Kim et al. 2011 & 0 & 17 & 4 & 12 & & $\because$ & 0.08 & {$[0.00 ; 1.35]$} & $0.4 \%$ \\
\hline Maraka et al. 2016 & 5 & 82 & 25 & 284 & & 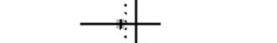 & 0.69 & {$[0.27 ; 1.75]$} & $3.9 \%$ \\
\hline Maraka et al. 2017 & 89 & 843 & 614 & 4562 & & $\stackrel{i}{+1}$ & 0.78 & {$[0.64 ; 0.97]$} & $76.1 \%$ \\
\hline Nazarpour et al. 2017 & 2 & 56 & 2 & 58 & & : & 1.04 & {$[0.15 ; 7.10]$} & $0.9 \%$ \\
\hline Nazarpour et al. 2018 & 0 & 183 & 0 & 183 & & & 1.00 & {$[0.02 ; 50.13]$} & $0.2 \%$ \\
\hline Wang et al. 2012 & 2 & 28 & 26 & 168 & & - & 0.46 & {$[0.12 ; 1.84]$} & $1.8 \%$ \\
\hline Zhao et al. 2018 & 1 & 62 & 1 & 31 & & & 0.50 & {$[0.03 ; 7.73]$} & $0.4 \%$ \\
\hline Random effects model & & 1675 & & 5667 & & 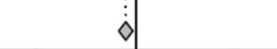 & \multirow[t]{2}{*}{0.79} & \multirow[t]{3}{*}[0.67;0.93]{} & \multirow[t]{3}{*}{$100.0 \%$} \\
\hline \multirow{2}{*}{\multicolumn{5}{|c|}{$\begin{array}{l}\text { Heterogeneity: } I^{2}=0 \%, \tau^{2}=0, p=0.77 \\
\text { Test for overall effect: } t_{9}=-3.18(p=0.01)\end{array}$}} & 1 & $T$ & & & \\
\hline & & & & & 0.01 & 0.1 & 100 & & \\
\hline
\end{tabular}

outcomes of children of women with SCH (Table 4). These RCTs showed that treatment with levothyroxine in women with $\mathrm{SCH}$ was not associated with behavioural or cognitive performance in the children at the age of 3 to 5 years $[37,38]$.

\section{Sensitivity analyses}

Two studies addressed whether levothyroxine treatment was associated with pregnancy outcomes among women with $\mathrm{SCH}$ caused by autoimmune disease (diagnosed by elevated TPOAb levels) [35]. Nazarpour et al. [35, 42]

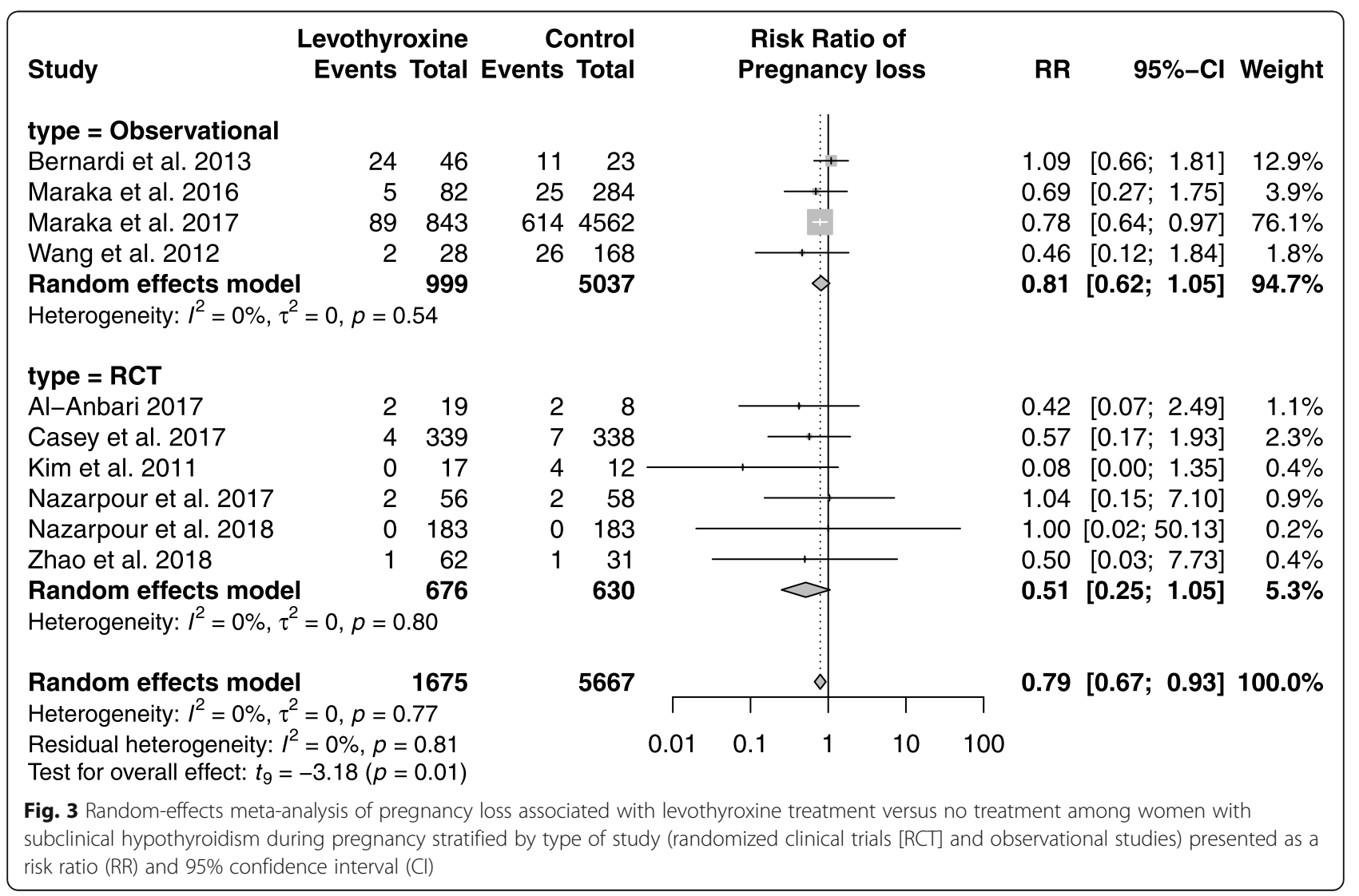


Table 3 Summary of binary outcomes between pregnant women with subclinical hypothyroidism treated with and without levothyroxine in randomized controlled trials and observational studies, expressed as risk ratios (RR) with 95\% confidence intervals $(\mathrm{Cl})$

\begin{tabular}{|c|c|c|c|c|}
\hline \multirow[b]{2}{*}{ Outcomes } & \multicolumn{2}{|c|}{ Observational studies } & \multicolumn{2}{|c|}{ Randomized controlled trials } \\
\hline & No. of studies & $\begin{array}{l}\text { Risk ratio } \\
(95 \% \mathrm{Cl})^{*}\end{array}$ & No. of studies & $\begin{array}{l}\text { Risk ratio } \\
(95 \% \mathrm{Cl})\end{array}$ \\
\hline \multicolumn{5}{|l|}{ Fetal } \\
\hline Intrauterine growth restriction & 2 & 1.06 (0.59 to 1.90$)$ & 0 & NA \\
\hline Placenta abruption & 2 & 1.06 (0.81 to 1.38$)$ & 3 & 0.93 (0.01 to 101.99) \\
\hline Spontaneous abortion & 1 & $0.46(0.12$ to 1.84$)$ & 3 & 0.44 (0.03 to 6.83) \\
\hline $\begin{array}{l}\text { Pregnancy loss (still births and } \\
\text { spontaneous abortions) }\end{array}$ & 4 & 0.81 (0.62 to 1.05$)$ & 6 & 0.51 (0.25 to 1.05$)$ \\
\hline \multicolumn{5}{|l|}{ Perinatal } \\
\hline Postpartum hemorrhage & 2 & 1.16 (1.06 to 1.27$)$ & 1 & 0.33 (0.06 to 1.89$)$ \\
\hline Premature rupture of membranes & 3 & 0.94 (0.52 to 1.70$)$ & 0 & NA \\
\hline Preterm delivery & 3 & 0.82 (0.13 to 4.98$)$ & 4 & $0.72(0.39$ to 1.35$)$ \\
\hline Preterm labour & 2 & 1.05 (0.56 to 1.97$)$ & 0 & NA \\
\hline Still birth & 4 & 0.75 (0.39 to 1.42$)$ & 0 & NA \\
\hline \multicolumn{5}{|l|}{ Neonatal } \\
\hline APGAR under 7 at five minutes & 2 & $0.24(0.00 \text { to } 68,937.70)^{*}$ & 1 & 0.66 (0.11 to 3.95$)$ \\
\hline Low birth weight & 3 & 0.55 (0.03 to 11.63$)$ & 2 & 0.86 (0.00 to 3722.22$)$ \\
\hline Neonatal death & 1 & 0.37 (0.02 to 6.83 ) & 1 & 0.33 (0.01 to 8.13$)$ \\
\hline
\end{tabular}

NA -non-applicable

*There were no events in the levothyroxine exposed groups

conducted a single-blinded RCT of pregnant women with $\mathrm{SCH}$ and elevated TPOAb. They found a decreased risk of preterm delivery associated with levothyroxine treatment compared to no treatment $(7.1 \%$ versus 23.7\%) [35]. Zhao et al. [42] randomized 93 pregnant women with $\mathrm{SCH}$ to treatment with levothyroxine or no treatment during the first and second trimesters of pregnancy. Although this study identified women with elevated TPOAb levels, the investigators did not compare the effect of treatment versus not on adverse pregnancy outcomes among women with $\mathrm{SCH}$ and elevated TPOAb levels. As such, a meta-analysis of the findings from these two studies was not possible.

Sensitivity analyses that excluded studies of women with a history of infertility or who conceived with fertility treatments [31, 39] and women with recurrent miscarriages [32] were consistent with those of our primary analysis (Figure S11). Furthermore, the results from the primary analysis remained consistent after excluding the study by Al-Anbari [31] (Figure S12). Given that there was no distribution in the quality of the RCTs, a stratified analysis on the quality of RCT studies was not feasible. When stratifying observational studies based on quality, there is a non-statistically, significantly decreased risk of pregnancy loss associated with levothyroxine treatment among women with $\mathrm{SCH}$ in studies considered at high risk and moderate risk of bias (Figure S13). In the influence analysis, the results remained consistent, showing an association between levothyroxine treatment versus no treatment was

Table 4 Summary of mean difference with 95\% confidence intervals (CI) between neonatal head-circumference and pediatric cognitive outcomes in pregnant women with subclinical hypothyroidism treated with and without levothyroxine

\begin{tabular}{lllll}
\hline Outcomes & Unit of measure & No. of Studies & Pooled Sample & $\begin{array}{l}\text { Mean Difference } \\
\mathbf{( 9 5 \% ~ C l )}\end{array}$ \\
\hline $\begin{array}{l}\text { Neonatal } \\
\quad \text { Neonatal head circumference (at birth) }\end{array}$ & $\mathrm{cm}$ & 2 & 1031 & $-0.042(-0.67$ to 0.58) \\
$\begin{array}{l}\text { Pediatric } \\
\text { Child Behaviour Checklist T-score at 3 }\end{array}$ & percentile & 2 & 1409 & $-0.50(-4.5$ to 3.5) \\
$\begin{array}{l}\text { years old } \\
\text { IQ at } 3 \text { to } 5 \text { years old }\end{array}$ & percentile & 2 & 1443 & $0.94(-23$ to 25) \\
\hline
\end{tabular}


associated with a decreased risk of pregnancy loss. However, this association was no longer significant when the study by Maraka et al. [34] was excluded. Finally, our findings remain consistent when a continuity correction of 0.1 was used in our meta-analyses (Table S3).

\section{Discussion}

In this systematic review and meta-analysis, we assessed the available evidence regarding the use of levothyroxine in treating $\mathrm{SCH}$ during pregnancy. We found that the use of levothyroxine among women with $\mathrm{SCH}$ was associated with a decreased risk of pregnancy loss and neonatal death relative to non-use. Although available data are limited, there is also evidence that levothyroxine treatment is associated with improved fetal outcomes, including reductions in fetal distress and macrosomia. We did not observe associations between treatment with levothyroxine and other adverse outcomes during pregnancy, labor and delivery and postpartum. Finally, there was no evidence of associations between levothyroxine use during pregnancy and cognitive outcomes in children. However, there was heterogeneity with respect to study populations and timing of initiation of levothyroxine between the included studies. Given the limited quality of the available data and its heterogeneity, additional high-quality studies are needed.

There is well-established evidence for the need to treat women with overt hypothyroidism during pregnancy as studies have shown that untreated hypothyroidism during pregnancy leads to increased risk of pregnancy complications, including increased risks of preterm birth, low birth weight, and stillbirth $[43,44]$. Throughout gestation, the fetus is dependent on the mother's supply of thyroid hormone, $[45,46]$ even after the fetal thyroid gland begins to function at approximately 12 weeks gestation. Thyroid hormone is a key moderator of fetal neurological development, fetal growth, and development of somatic tissue $[8,15]$. As an adaptation to increased demand, physiological changes in the mother result in elevated maternal serum thyroxine concentration throughout pregnancy $[8,15,46]$. Furthermore, given that thyroid hormone plays an important role in brain development, untreated hypothyroidism during pregnancy may lead to deficiencies in fetal neurocognitive development and lower intelligence quotient (IQ) in the offspring [47, 48]. Thus, based on the known essential role of thyroid hormone during pregnancy, it is possible that untreated $\mathrm{SCH}$ can lead to adverse outcomes during pregnancy including an increase in pregnancy loss [49].

A recent systematic review and meta-analysis of studies comparing women with $\mathrm{SCH}$ and euthyroid women during pregnancy found that $\mathrm{SCH}$ was associated with an increased risk of multiple adverse maternal and fetal outcomes [10], including pregnancy loss (RR: 2.01; 95\% CI: 1.66-2.44), placental abruption (RR: 2.14 ; 95\% CI: 1.23-3.70), premature rupture of membranes (PROM) (RR: 1.43; 95\% CI: 1.04-1.95) and neonatal death (RR: 2.58; 95\% CI: 1.41-4.73). A recent systematic review and meta-analysis of RCTs assessed whether levothyroxine treatment during pregnancy among women with $\mathrm{SCH}$ has an impact on obstetrical and fetal outcomes [16]. This study included 3 trials and found no difference in obstetrical and neonatal outcomes, including childhood IQ and neurocognitive outcomes among children born to women with $\mathrm{SCH}$ who were treated with levothyroxine compared to those who received no treatment [16]. Thus, evidence from RCTs suggests that there is no significant reduction in adverse fetal outcomes associated with levothyroxine treatment in women with $\mathrm{SCH}$. Finally, a meta-analysis by Rao et al. [17] showed that levothyroxine treatment among women with $\mathrm{SCH}$ and women with thyroid autoimmune disease was associated with a decreased risk of pregnancy loss and preterm birth compared to women who received no treatment. In a sub-group analysis of women with $\mathrm{SCH}$, levothyroxine treatment was associated with a decreased risk of pregnancy loss compared to no treatment (RR: 0.43; 95\% CI: $0.26-0.72$ ) but there was no association between levothyroxine treatment and preterm birth (RR: 0.67; 95\% CI: 0.41-1.12). Although this meta-analysis included fewer studies than our meta-analysis, [17] the findings are consistent with the current study. Nazarpour et al. [18] performed a meta-analysis comparing women with $\mathrm{SCH}$ during pregnancy treated with levothyroxine with women who were not treated or were euthyroid. In a subgroup analysis, they compared women with $\mathrm{SCH}$ who were treated with levothyroxine versus no treatment, and found a decreased risk of pregnancy loss associated with levothyroxine treatment (odds ratio: 0.78; 95\% CI: 0.66-0.94). Although the types of studies included in this meta-analysis differed from ours and included studies that had different TSH targets for treatment of SCH (i.e. targeted TSH to $<4.2 \mathrm{mIU} / \mathrm{L}$ [50]), the findings are consistent with our study. In addition, this previous meta-analysis did not assess neonatal and cognitive outcomes in children.

The majority of the studies performed to date initiated levothyroxine during the first trimester with only two studies addressing the effects of initiating levothyroxine at other times during pregnancy [40]. Ju et al. [40, 42] found that initiation of levothyroxine during the first trimester decreased the risk of PROM, gestational diabetes, postpartum hemorrhage, gestational hypertension, and fetal macrosomia compared to women who received levothyroxine treatment in the second and third trimester [40]. Zhao et al. [42] also showed that initiation of levothyroxine during the first trimester was associated 
with a decreased risk of adverse pregnancy outcomes (i.e. composed of premature labor, pregnancy loss, postpartum hemorrhage, and low birth weight) compared to women who were initiated on treatment during the second trimester (incidence of pregnancy complications among women treated during first trimester versus second trimester: $3 / 31$ versus $13 / 31 ; p=0.004)$. None of the other studies in our meta-analysis addressed whether later initiation of levothyroxine had any impact on pregnancy outcomes.

The presence of TPOAb has been shown to increase the risk of pregnancy loss by approximately two-fold among women with $\mathrm{SCH}[51,52]$. Furthermore, studies have shown that treatment with levothyroxine among women with positive TPOAb levels during pregnancy decreased the rate of pregnancy complications regardless of thyroid function status (i.e. $\mathrm{SCH}$ and euthyroid women) [53-55]. In the present meta-analysis, two of the included studies found that levothyroxine treatment in women with $\mathrm{SCH}$ and elevated TPOAb was associated with a lower risk of a composite endpoint of gestational hypertension, preeclampsia, anemia, and gestational diabetes [42] and preterm delivery [35]. In contrast, two recent RCTs found that levothyroxine treatment of TPOAb positive women who had normal thyroid function during pregnancy did not affect pregnancy outcomes $[56,57]$. However, based on the current evidence, women with $\mathrm{SCH}$ and elevated TPOAb may benefit from levothyroxine treatment.

Levothyroxine treatment for $\mathrm{SCH}$ during pregnancy may decrease the risk of pregnancy loss among women with infertility $[9,31,39]$, although the number of studies in this area is few and the results are conflicting. One study included in our meta-analysis found no association between rates of live births and levothyroxine treatment among women with $\mathrm{SCH}$ and recurrent early pregnancy loss [32]. In contrast, the studies by Kim et al. [39] and $\mathrm{Al}$-Anbari [31] found that levothyroxine treatment of $\mathrm{SCH}$ among women with infertility, undergoing in vitro fertilization and intracytoplasmic sperm injection, had improved embryo quality and embryo implantation rate compared to women who were not treated. However, the studies were small and further research is needed to determine whether levothyroxine treatment of $\mathrm{SCH}$ improves pregnancy outcomes among women with infertility or recurrent pregnancy loss.

\section{Limitations}

Our study has several potential limitations. First, statistical heterogeneity was present in many of our analyses. This heterogeneity is likely due to differences in study design, sample populations, geographical location, and temporal differences in the timing of levothyroxine initiation during pregnancy. There were also some differences in the definition of pregnancy loss across studies, a lack of information relating to TSH levels used to define $\mathrm{SCH}$, and the timing of initiation of levothyroxine therapy. Given this heterogeneity, we used random-effects models to account for the within- and between-study variability. Second, our study defined $\mathrm{SCH}$ using the TSH cut-off limit of $2.5 \mathrm{mIU} / \mathrm{L}$ recommended by the 2011 ATA guidelines [21]. The recent 2017 ATA guidelines recommend various TSH cut-offs based on the presence of thyroid autoimmune disease (i.e. presence of TPOAb) [9] for initiation of levothyroxine treatment. Given that these more recent guidelines heavily rely on the evidence of thyroid autoimmune disease, the use of this definition in our meta-analysis would have resulted in far fewer included studies and could have been affected by selection bias due to the systematic exclusion of older studies. Although the definition of $\mathrm{SCH}$ and recommendations for treatment during pregnancy has changed over time, our study provides evidence for treatment of $\mathrm{SCH}$ during pregnancy in a more generalized population. Further studies would be required to address the benefits of treating $\mathrm{SCH}$ during pregnancy using the recommendations from the 2017 ATA guidelines [9]. Third, outcomes were inconsistently reported, and some of our analyses therefore included a small number of studies. Consequently, some of our estimated treatment effects are accompanied by wide CIs. Due to the small number of studies included in our meta-analysis, our ability to examine the impact of study-level covariates on estimated treatment effects via meta-regression was limited. Fourth, we assessed the association between levothyroxine use and the occurrence of several potential adverse outcomes during pregnancy. The potential for chance findings due to multiple testing should thus be considered when interpreting our findings. Fifth, as is true with all knowledge syntheses, we cannot rule out the possibility of publication bias. Given the small number of included studies, there were an insufficient number of studies to assess publication bias through the use of funnel plots. Sixth, since there is no distribution in the quality of RCTs, we were unable to perform stratified analysis on the quality of these studies. Seventh, the finding of a decreased risk of pregnancy loss associated with levothyroxine treatment versus no treatment was significantly impacted by the findings from Maraka et al. [34] as the other studies are smaller, leading to inconclusive results. Thus, this emphasizes the need to conduct a meta-analysis in this area of research. Eighth, we used a continuity correction of 0.5 to allow for the inclusion of zero-event studies. While this approach reduces potential selection bias, it can introduce bias for small studies with imbalances in numbers. Ninth, the number of studies that addressed the presence of TPOAb was few $[35,42]$. We were therefore not 
able to perform a subgroup analyses among women with $\mathrm{SCH}$ secondary to an autoimmune condition. These analyses would have been clinically relevant given that the concurrent presence of an autoimmune disorder may affect fetal outcomes among women with $\mathrm{SCH}[51,52]$. Tenth, due to the paucity of RCTs in this area of research, we performed meta-analyses of RCTs and observational studies, which may be affected by confounding. However, we conducted stratified analyses to demonstrate findings from RCTs and observational studies separately. Finally, the literature search was conducted on July 18, 2018. Additional studies may have been published since this time.

\section{Conclusion}

This systematic review and meta-analysis found that, compared with non-use, levothyroxine treatment was associated with decreased risks of pregnancy loss and neonatal death among pregnant women with $\mathrm{SCH}$. There was no association between levothyroxine treatment and the risk of other adverse outcomes including outcomes during labour and delivery, and cognitive status in children at 3 or 5 years of age. However, the quality of many of the included studies was modest and important heterogeneity was present. Consequently, further studies are required to address whether levothyroxine treatment among women with $\mathrm{SCH}$ improves pregnancy outcomes if given earlier during pregnancy, in women with autoimmune thyroid disease, and in women with a history of infertility or recurrent pregnancy loss.

\section{Supplementary Information}

The online version contains supplementary material available at https://doi. org/10.1186/s12902-021-00699-5.

\section{Additional file 1.}

\section{Abbreviations}

ATA: American Thyroid Association; FT4: Free thyroxine; IQ: Intelligence quotient; PRESS: Peer Review of Electronic Search Strategies; PRIS MA: Preferred Reporting Items for Systematic Reviews and Meta-Analyses; PROM: Premature rupture of membranes; RCTs: Randomized controlled trials; ROBINS: Risk of Bias In Non-randomised Studies of Interventions; RR: Risk ratio; SCH: Subclinical hypothyroidism; TPOAb: Anti-thyroid peroxidase antibodies; TSH: Thyroid stimulating hormone

\section{Acknowledgements}

None.

\section{Authors' contributions}

All authors contributed to the study design and writing of the manuscript. F.F. performed the literature search. M.B. and O.Y. performed the screening of articles to be included in the systematic review, data extraction and quality analyses of studies. I.K. was the third reviewer who resolved any conflicts that arose during the screening of articles, data extraction, and quality analyses. All authors (M.B., O.Y., S.M.G., F.Y.E.F., I.K., K.B.F.) contributed to study design, interpretation of data, and reviewed and approved the final manuscript. K.B.F. is the guarantor of this work, had full access to the data and takes responsibility for the integrity of the data and data analyses.

\section{Funding}

Dr. Filion holds a Senior salary support award from the Fonds de recherche Québec - Santé (FRSQ; Quebec Foundation for Health Research) and a William Dawson Scholar award from McGill University. Dr. Grandi holds a postdoctoral fellowship from the Canadian Institutes of Health. Dr. Yu holds a FRQS Junior 1 salary support award. The funding bodies played no role in the design of the study and collection, analysis, and interpretation of data and in writing the manuscript.

\section{Availability of data and materials}

Not applicable.

Ethics approval and consent to participate

Not applicable.

\section{Consent for publication}

Not applicable.

\section{Competing interests}

No conflict of interests to declare.

\section{Author details}

${ }^{1}$ Department of Biology, McGill University, Montreal, Quebec, Canada. ${ }^{2}$ Department of Medicine, McGill University, Montreal, Quebec, Canada. ${ }^{3}$ Division of Endocrinology, Department of Medicine, Jewish General Hospital, Montreal, Quebec, Canada. ${ }^{4}$ Center for Clinical Epidemiology, Lady Davis Institute, Jewish General Hospital, Montreal, Quebec H3T 1E2, Canada. ${ }^{5}$ Epidemiology Branch, Division of Intramural Population Health Research, Eunice Kennedy Shriver National Institute of Child Health and Human Development, National Institutes of Health, Bethesda, MD, USA. ${ }^{6}$ Department of McGill University Library \& Archives, McGill University, Montreal, Quebec, Canada. ${ }^{7}$ Department of Epidemiology, Biostatistics, and Occupational Health, McGill University, Montreal, Quebec, Canada.

Received: 18 June 2020 Accepted: 11 February 2021

Published online: 27 February 2021

\section{References}

1. Negro R, Stagnaro-Green A. Diagnosis and management of subclinical hypothyroidism in pregnancy. BMJ (Clinical research ed). 2014;349:g4929.

2. van den Boogaard E, Vissenberg R, Land JA, van Wely M, van der Post JA, Goddijn M, Bisschop PH. Significance of (sub) clinical thyroid dysfunction and thyroid autoimmunity before conception and in early pregnancy: a systematic review. Hum Reprod Update. 2011;17(5):605-19.

3. Arbib N, Hadar E, Sneh-Arbib O, Chen R, Wiznitzer A, Gabbay-Benziv R. First trimester thyroid stimulating hormone as an independent risk factor for adverse pregnancy outcome. J Maternal-fetal Neonatal Med. 2017:30(18): 2174-8

4. Sferruzzi-Perri AN, Vaughan OR, Forhead AJ, Fowden AL. Hormonal and nutritional drivers of intrauterine growth. Curr Opin Clin Nutr Metab Care. 2013;16(3):298-309.

5. Moog NK, Entringer S, Heim C, Wadhwa PD, Kathmann N, Buss C. Influence of maternal thyroid hormones during gestation on fetal brain development. Neuroscience. 2017;342:68-100

6. Dickens LT, Cifu AS, Cohen RN. Diagnosis and management of thyroid disease during pregnancy and the postpartum period. Jama. 2019;321(19): 1928-9.

7. Korevaar TIM, Derakhshan A, Taylor PN, Meima M, Chen L, Bliddal S, Carty DM, Meems M, Vaidya B, Shields B, et al. Association of thyroid function test abnormalities and thyroid autoimmunity with preterm birth: a systematic review and meta-analysis. (1538-3598 (Electronic)). JAMA. 2019;322(7):632-41.

8. Forhead AJ, Fowden AL. Thyroid hormones in fetal growth and prepartum maturation. J Endocrinol. 2014;221(3):R87-r103.

9. Alexander EK, Pearce EN, Brent GA, Brown RS, Chen H, Dosiou C, Grobman WA, Laurberg P, Lazarus JH, Mandel SJ, et al. 2017 guidelines of the American Thyroid Association for the diagnosis and Management of Thyroid Disease during Pregnancy and the postpartum. Thyroid. 2017;27(3): 315-89.

10. Maraka S, Ospina NM, O'Keeffe DT. Espinosa De Ycaza AE, Gionfriddo MR, Erwin PJ, Coddington CC, 3rd, Stan MN, Murad MH, Montori VM: subclinical 
hypothyroidism in pregnancy: a systematic review and Meta-analysis. Thyroid. 2016;26(4):580-90.

11. Thompson W, Russell G, Baragwanath G, Matthews J, Vaidya B. Maternal thyroid hormone insufficiency during pregnancy and risk of neurodevelopmental disorders in offspring: A systematic review and metaanalysis. Clin Endocrinol (Oxf). 2018;88(4):575-84.

12. Zhang $Y$, Wang $H$, Pan $X$, Teng $W$, Shan Z. Patients with subclinical hypothyroidism before 20 weeks of pregnancy have a higher risk of miscarriage: A systematic review and meta-analysis. PLoS One. 2017;12(4): e0175708.

13. Casey BM, Dashe JS, Wells CE, Mclntire DD, Byrd W, Leveno KJ, Cunningham FG. Subclinical hypothyroidism and pregnancy outcomes. Obstet Gynecol. 2005;105(2):239-45.

14. Negro R, Stagnaro-Green A. Diagnosis and management of subclinical hypothyroidism in pregnancy. BMJ. 2014;349:94929.

15. Chan S, Boelaert K. Optimal management of hypothyroidism, hypothyroxinaemia and euthyroid TPO antibody positivity preconception and in pregnancy. Clin Endocrinol. 2015;82(3):313-26.

16. Yamamoto JM, Benham JL, Nerenberg KA, Donovan LE. Impact of levothyroxine therapy on obstetric, neonatal and childhood outcomes in women with subclinical hypothyroidism diagnosed in pregnancy: a systematic review and meta-analysis of randomised controlled trials. BMJ Open. 2018;8(9):e022837.

17. Rao M, Zeng Z, Zhou F, Wang H, Liu J, Wang R, Wen Y, Yang Z, Su C, Su Z, et al. Effect of levothyroxine supplementation on pregnancy loss and preterm birth in women with subclinical hypothyroidism and thyroid autoimmunity: a systematic review and meta-analysis. Hum Reprod Update. 2019:25(3):344-61.

18. Nazarpour S. Levothyroxine treatment and pregnancy outcomes in women with subclinical hypothyroidism: a systematic review and meta-analysis. Arch Gynecol Obstet. 2019;300(4):805-19.

19. Moher D, Liberati A, Tetzlaff J, Altman DG. Preferred reporting items for systematic reviews and meta-analyses: the PRISMA statement. BMJ (Clinical research ed). 2009:339:b2535.

20. McGowan J, Sampson M, Salzwedel DM, Cogo E, Foerster V, Lefebvre C. PRESS Peer Review of Electronic Search Strategies: 2015 Guideline Statement. J Clin Epidemiol. 2016;75:40-6.

21. Stagnaro-Green A, Abalovich M, Alexander E, Azizi F, Mestman J, Negro R, Nixon A, Pearce EN, Soldin OP, Sullivan S, et al. Guidelines of the American Thyroid Association for the diagnosis and management of thyroid disease during pregnancy and postpartum. Thyroid. 2011;21(10): 1081-125.

22. Higgins JP, Altman DG, Gotzsche PC, Juni P, Moher D, Oxman AD, Savovic J, Schulz KF, Weeks L, Sterne JA. The Cochrane Collaboration's tool for assessing risk of bias in randomised trials. BMJ (Clinical research ed). 2011; 343:d5928.

23. Sterne JA, Hernan MA, Reeves BC, Savovic J, Berkman ND, Viswanathan $M$, Henry D, Altman DG, Ansari MT, Boutron I, et al. ROBINS-l: a tool for assessing risk of bias in non-randomised studies of interventions. BMJ (Clinical research ed). 2016;355:14919.

24. Shrier IBJ-F, Steele RJ, Platt RW, Furlan A, Kakuma R, Brophy J, Rossignol M. Should meta-analyses of interventions include observational studies in addition to randomized controlled trials? A critical examination of underlying principles. Am J Epidemiol. 2007;166(10):1203-9 doi: 12101093/ aje/kwm1189 Epub 2007 Aug 1221

25. DerSimonian R, Laird N. Meta-analysis in clinical trials. Control Clin Trials. 1986;7(3):177-88.

26. Jackson $\mathrm{D}$. Confidence intervals for the between-study variance in random effects meta-analysis using generalised Cochran heterogeneity statistics. Res Synth Methods. 2013;4(3):220-9.

27. Hartung J, Knapp G. A refined method for the meta-analysis of controlled clinical trials with binary outcome. Stat Med. 2001;20(24):3875-89.

28. Systematic reviews in health care. Meta-analysis in context. London: BMJ Publishing Group; 1995.

29. Schwarzer G. Meta: an R package for meta-analysis. R News. 2007;7(3):40-5.

30. R Development Core team: $\mathrm{R}$ : a language and environment for statistical computing. In. Vienna, Austria: R Foundation for statistical Computing; 2010.

31. Al-Anbari L. Thyroxine supplementation improve intrauterine insemination outcome in patients with subclinical hypothyroidism. J Pharm Sci Res. 2017; $9(10): 1768-72$
32. Bernardi LA, Cohen RN, Stephenson MD. Impact of subclinical hypothyroidism in women with recurrent early pregnancy loss. Fertil Steril. 2013;100(5):1326-31.

33. Maraka S, Singh Ospina NM, O'Keeffe DT, Rodriguez-Gutierrez R, Espinosa De Ycaza AE, Wi Cl, Juhn YJ, Coddington CC 3rd, Montori VM, Stan MN. Effects of levothyroxine therapy on pregnancy outcomes in women with subclinical hypothyroidism. Thyroid. 2016;26(7):980-6.

34. Maraka S, Mwangi R, McCoy RG, Yao X, Sangaralingham LR, Singh Ospina NM, O'Keeffe DT, De Ycaza AE, Rodriguez-Gutierrez R, Coddington CC 3rd, et al. Thyroid hormone treatment among pregnant women with subclinical hypothyroidism: US national assessment. BMJ (Clinical research ed). 2017; 356:6865.

35. Nazarpour S, Ramezani Tehrani F, Simbar M, Tohidi M, Alavi Majd H, Azizi F. Effects of levothyroxine treatment on pregnancy outcomes in pregnant women with autoimmune thyroid disease. Eur J Endocrinol. 2017;176(2): 253-65.

36. Nazarpour S, Ramezani Tehrani F, Simbar M, Tohidi M, Minooee S, Rahmat M, Azizi F. Effects of levothyroxine on pregnant women with subclinical hypothyroidism, negative for thyroid peroxidase antibodies. J Clin Endocrinol Metab. 2018;103(3):926-35.

37. Casey BM, Thom EA, Peaceman AM, Varner MW, Sorokin Y, Hirtz DG, Reddy UM, Wapner RJ, Thorp JM Jr, Saade G, et al. Treatment of subclinical hypothyroidism or Hypothyroxinemia in pregnancy. N Engl J Med. 2017; 376(9):815-25.

38. Lazarus JH, Bestwick JP, Channon S, Paradice R, Maina A, Rees R, Chiusano E, John R, Guaraldo V, George LM, et al. Antenatal thyroid screening and childhood cognitive function. N Engl J Med. 2012;366(6):493-501.

39. Kim CH, Ahn JW, Kang SP, Kim SH, Chae HD, Kang BM. Effect of levothyroxine treatment on in vitro fertilization and pregnancy outcome in infertile women with subclinical hypothyroidism undergoing in vitro fertilization/intracytoplasmic sperm injection. Fertil Steril. 2011;95(5):1650-4.

40. Ju R, Lin L, Long Y, Zhang J, Huang J. Clinical efficacy of therapeutic intervention for subclinical hypothyroidism during pregnancy. Gene Mol Res. 2016;15(4).

41. Wang S, Teng WP, Li JX, Wang WW, Shan ZY. Effects of maternal subclinical hypothyroidism on obstetrical outcomes during early pregnancy. J Endocrinol Investig. 2012;35(3):322-5.

42. Zhao L, Jiang G, Tian X, Zhang X, Zhu T, Chen B, Wang Y, Ma Q. Initiation timing effect of levothyroxine treatment on subclinical hypothyroidism in pregnancy. Gynecol Endocrinol. 2018:1-4.

43. Abalovich M, Gutierrez S, Alcaraz G, Maccallini G, Garcia A, Levalle O. Overt and subclinical hypothyroidism complicating pregnancy. Thyroid. 2002;12(1): 63-8.

44. Teng W, Shan Z, Patil-Sisodia K, Cooper DS. Hypothyroidism in pregnancy. The lancet Diabetes \& endocrinology. 2013;1 (3):228-37.

45. Glinoer $\mathrm{D}$. The regulation of thyroid function in pregnancy: pathways of endocrine adaptation from physiology to pathology. Endocr Rev. 1997;18(3): 404-33.

46. de Escobar GM, Obregon MJ, del Rey FE. Maternal thyroid hormones early in pregnancy and fetal brain development. Best Pract Res Clin Endocrinol Metab. 2004;18(2):225-48.

47. Li Y, Shan Z, Teng W, Yu X, Li Y, Fan C, Teng X, Guo R, Wang H, Li J, et al. Abnormalities of maternal thyroid function during pregnancy affect neuropsychological development of their children at 25-30 months. Clin Endocrinol. 2010;72(6):825-9.

48. Haddow JE, Palomaki GE, Allan WC, Williams JR, Knight GJ, Gagnon J, O'Heir CE, Mitchell ML, Hermos RJ, Waisbren SE, et al. Maternal thyroid deficiency during pregnancy and subsequent neuropsychological development of the child. N Engl J Med. 1999;341(8):549-55.

49. Sarkar D. Recurrent pregnancy loss in patients with thyroid dysfunction. Indian J Endocrinol Metab. 2012;16(Suppl 2):2230-8210.

50. Abdel Rahman AH AAH, Abbassy AA: Improved in vitro fertilization outcomes after treatment of subclinical hypothyroidism in infertile women. Endocr Pract 2010, 16(5):792-797. doi: 7https://doi.org/10.4158/EP09365.OR.

51. Stagnaro-Green A, Roman SH, Cobin RH, el-Harazy E, Alvarez-Marfany M, Davies TF. Detection of at-risk pregnancy by means of highly sensitive assays for thyroid autoantibodies. JAMA. 1990;264(11):1422-5.

52. Chen L, Hu R. Thyroid autoimmunity and miscarriage: a meta-analysis. Clin Endocrinol. 2011;74(4):513-9.

53. Negro R, Schwartz A, Gismondi R, Tinelli A, Mangieri T, Stagnaro-Green A. Universal screening versus case finding for detection and treatment of 
thyroid hormonal dysfunction during pregnancy. J Clin Endocrinol Metab. 2010;95(4):1699-707.

54. Lepoutre T, Debieve F, Gruson D, Daumerie C. Reduction of miscarriages through universal screening and treatment of thyroid autoimmune diseases. Gynecol Obstet Investig. 2012;74(4):265-73.

55. Negro R, Formoso G, Mangieri T, Pezzarossa A, Dazzi D, Hassan H.

Levothyroxine treatment in euthyroid pregnant women with autoimmune thyroid disease: effects on obstetrical complications. J Clin Endocrinol Metab. 2006;91(7):2587-91.

56. Dhillon-Smith RK, Middleton LJ, Sunner KK, Cheed V. Levothyroxine in Women with Thyroid Peroxidase Antibodies before Conception. N Engl J Med. 2019;380(14):1316-25

57. Wang H, Gao H, Chi H, Zeng L, Xiao W, Wang Y, Li R, Liu P, Wang C, Tian $\mathrm{Q}$ et al. Effect of levothyroxine on miscarriage among women with Normal thyroid function and thyroid autoimmunity undergoing in vitro fertilization and embryo transfer: a randomized clinical trial. Jama. 2017;318(22):2190-8.

\section{Publisher's Note}

Springer Nature remains neutral with regard to jurisdictional claims in published maps and institutional affiliations.

Ready to submit your research? Choose BMC and benefit from:

- fast, convenient online submission

- thorough peer review by experienced researchers in your field

- rapid publication on acceptance

- support for research data, including large and complex data types

- gold Open Access which fosters wider collaboration and increased citations

- maximum visibility for your research: over $100 \mathrm{M}$ website views per year

At BMC, research is always in progress.

Learn more biomedcentral.com/submissions 